\title{
Observations on the presence of a cyanophilic perispore in the spores of the Pezizales
}

\author{
Harri Harmaja \\ Botanical Museum, University of Helsinki, SF-00170 Helsinki, Finland
}

\begin{abstract}
Harmaja, H. 1974: Observations on the presence of a cyanophilic perispore in the spores of the Pezizales. - Karstenia 14: 123-125.

The mature spores of the Pezizales, both those with ornamentations and those with a completely smooth surface, can be divided into two groups on the basis of the presence versus absence of cyanophilic substance outside the true spore wall. When present this substance, whether smooth or ornamented, perhaps always forms a continuous sheath surrounding the spore. A temporary cyanophilic sheath surrounds the immature spores of many species of the order, vanishing completely towards spore maturity. In preliminary observations on 31 genera of the order, three spore types could be distinguished in the species studied: 1) the Morchella type (or perisporeless type), 2) the Otidea type (or temporarily perisporous type) and 3) the Peziza type (or persistently perisporous type). These spore types will probably be most useful at the generic level in the taxonomy of the Pezizales, but possibly also at the family level. Some new observations of certain other taxonomically interesting characters are also given; e.g. the gaseous de Bary bubbles inside the spores (in heated cotton blue) are reported to be much more frequent in the Pezizales than has hitherto been known.
\end{abstract}

During recent studies on certain genera of the Pezizales, I observed interesting differences at the generic level in the outermost layer or layers of the spores. It has been known for some time that the ornamentation of $\mathrm{Pe}$ zizales spores may be either cyanophilic or cyanophobic (see e.g. Le GaL 1947). On the other hand, almost no attention has been paid to the fact that the completely smooth outer layers or coats of the mature spores may also be divided into two groups as regards their behaviour when heated in cotton blue. When cyanophilic, the sheath surrounding these smooth spores sometimes seems to be composed of at least two different layers: an outer \pm thin film, which might be called the perispore, and apparently softer matter between this film and the true spore wall, which might be called the periplasm. According to Le GaL (1947), similar layers can often be distinguished in the cyanophilic matter of ornamented spores. However, the cyanophilic coat is often so thin that it is impossible to tell with a light microscope whether it is composed of two parts or not (for the sake of brevity, in this paper the word »perispore» is used for all cyanophilic matter outside the true spore wall).

A second important feature is the presence of a temporary continuous cyanophilic coat, or sheath, on the immature spores of a number of species. It begins to develop at some stage of the spore maturation, reaches its maximal thickness while the spores are still immature, and may infrequently even form apiculi at the spore ends, disappearing completely as full maturity is achieved. As no distinct peeling has been observed, the cyanophilic matter most probably dissolves but, at least in some cases, it may simply 
alter physically (or chemically), so that it is no longer able to absorb the dye.

In all the cases studied the rigid $\gg$ true spore wall» (which often seems to be composed of more than one layer even under the light microscope) appears constantly cyanophobic (and mostly hyaline) right from the beginning.

The spore contents also display specific (or perhaps mostly generic?) variation in their response to cotton blue, which must be distinguished carefully from the response of the perispore, since it is often difficult to tell whether the blue colour of the spore is exclusively due to the cyanophilic contents of the spore or does it result from a cyanophilic perispore. In the latter case it is apparently impossible to tell if also the contents are cyanophilic. At the earliest stages at which they became discernible, the contents of all the young spores studied were cyanophobic of very weakly cyanophilic. Their capacity to absorb the dye usually increases with age, but in many cases they become cyanophobic again in mature spores.

(These studies also revealed that the gaseous de Bary bubbles of mature spores, as discernible in heated cotton blue, are far more frequent than has been reported in the literature. They almost always are present in spores which lack any cyanophilic matter, both on the surface and in the contents. In a few exceptional cases, these bubbles may possibly be present in young spores and absent from mature ones, but this matter must be studied in more detail).

LE GAL (1947) mainly examined and classified spores with ornamentations (and added very much to our knowledge of the structure and variability of the Pezizales spore). However, in my opinion, it is more natural to begin a study of the correlation between spore types and the taxonomic classification of the fungi in question by considering all the spores, both those with smooth and rough surfaces. One classificatory spore character which seems very practical at the light microscope level, till the apparently decisive wall structures of the species have been clarified with the transmission electron microscope, is the presence versus absence in mature spores of cyanophilic matter (smooth sheath, warts, ornamentations, etc.) outside the true spore wall (quite obviously the dis- tinction between the smooth and the ornamented perispore, not infrequently overemphasized in generic taxonomy, has its main application in the infrageneric taxonomy; the presence of a common structure in two species is more decisive than such a fact that this structure is smooth in one of them and rough in the other). The spores that are devoid of such matter when mature can be further divided into those that lack it throughout their development and those that have a temporary cyanophilic perispore at certain immature stages. The surface of the mature spore may apparently be smooth or ornamented in all three types.

The following preliminary grouping is based on a study of the type species (when possible) and often additional species of a large group of the genera of the order Pezizales. The genera with minute fruit bodies are, however, poorly represented in this group. The present spore character should of course be examined in all the species of the order, so that as much information as possible may be obtained for improving the taxonomical classification within the order. However, more detailed studies of a few cases seem to indicate that spore types are constant within genera and the present character will thus probably be most valuable for delimiting genera, although it may also be useful at the family level.

1. Morchella type (or perisporeless type). - Cyanophilic perispore-perisplasm structure absent at all stages of spore development. If the spore contents are cyanophilic in mature spores (as they were in most of the genera studied), the spores, however, turn blue when heated in cotton blue, but with an adequate magnification it is observed that exclusively the contetns absorb the dye. If the spore contents are cyanophobic (Pithya, Pseudoplectania), the mature spores naturally are completely hyaline (the contents of immature spores are, however, cyanophilic also here). Oil drops are infrequent in mature spores. De Bary bubbles are mostly lacking in mature spores in heated cotton blue. De Bary bubbles present in: Pithya,Pseudoplectania; absent from: Caloscypha, Disciotis, Karstenella, Morchella, Verpa.

2. Otidea type (or temporarily perisporous type). - A cyanophilic perispore-perisplasm structure is present only in immature spores 
(though not at the very youngest stages) and vanishes completely towards maturity. The cyanophilic matter mostly begins to develop evenly all over the spore wall, but sometimes forms apiculi at the spore ends. The perispore is mostly smooth but sometimes slightly roughened, at least when observed under an oil immersion lens at a high magnification. (The young spores of Geopyxis carbonaria (Pers.) Sacc. differ slightly in possessing a loose cyanophobic perispore in addition to the layer of cyanophilic matter, or periplasm, adhering to the spore wall. This perispore in G. carbonaria is wrinkled or folded, and towards maturity, while the cyanophilic periplasm is disappearing, it apparently gets appressed to the spore wall since the mature spores possess very delicate cyanophobic, mostly striate, markings which are most distinct towards the spore ends. Hitherto the spores of this species have been considered smooth). The spore contents are always cyanophobic in the mature spores, which are thus completely hyaline in heated cotton blue. Oil drops are present or absent in mature spores. De Bary bubbles are almost always present in mature spores in heated cotton blue. De Bary bubbles present in: Byssonectria, Flavoscypha, Geopora, Otidea, Pseudombrophila, Pseudorhizina, Pulparia, Pulvinula; absent from: Geopyxis, Pyronema.

3. Peziza type (or persistently perisporous type). - A cyanophilic perispore-periplasm structure is present in both immature (though not at the very youngest stages) and mature spores. It may be thin, not strongly cyanophilic (as in the Sarcoscyphineae) and as it often is tightly appressed to the spore wall, it may be difficult to discern. The mature spores are thus paler or darker blue in colour when heated in cotton blue (and it is naturally difficult to judge the response of the contents of the spore to cotton blue). The cyanophilic matter may begin to develop either evenly all over the spore wall, or as apical caps at the spore ends (e.g. in Gyromitra and Rhizina). It may increase or decrease (as in Tarzetta) in thickness towards spore maturity. As is well known, the perisporial substance is relatively soft and it often exhibits many kinds of unevenness, or ornamentation, towards spore maturity. All the fairly numerous genera with species which possess cyanophilic ornamentations in their mature spores belong here. Oil drops are mostly present, rarely lacking, in mature spores. De Bary bubbles are mostly lacking in mature spores in heated cotton blue. De Bary bubbles present in: Scutellinia, Sowerbyella; absent from (present, however, in very occasional spores of Gyromitra ambigua): Aleuria, Gyromitra, Helvella, Humaria, Leucoscypha, Microstoma, Peziza, Rhizina, Sarcoscypha, Sarcosoma, Tarzetta, Urnula.

Acknowledgements. - I wish to express my thanks to Prof. J. A. Nannfeldt and Dr. R. Santesson of Uppsala (UPS) for placing certain specimens at my disposal.

\section{REFERENCE}

LE GAL, M. 1947: Recherches sur les ornementations sporales des Discomycètes operculés. - Ann. Sci. Nat. XI: Bot. 8: 73-297. 